\title{
The Potential for Buoyant Displacement Gas Release Events in Tank 241-SY-102 after Waste Transfer from Tank 241-SY-101
}

\author{
BE Wells \\ PA Meyer \\ G Chen
}

April 2000

Prepared for

the U.S. Department of Energy

under Contract DE-AC06-76RLO 1830

Pacific Northwest National Laboratory

Richland, Washington 99352 


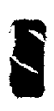

)

।

I

I

I 


\section{DISCLAIMER}

This report was prepared as an account of work sponsored by an agency of the United States Government. Neither the United States Government nor any agency thereof, nor any of their employees, make any warranty, express or implied, or assumes any legal liability or responsibility for the accuracy, completeness, or usefulness of any information, apparatus, product, or process disclosed, or represents that its use would not infringe privately owned rights. Reference herein to any specific commercial product, process, or service by trade name, trademark, manufacturer, or otherwise does not necessarily constitute or imply its endorsement, recommendation, or favoring by the United States Government or any agency thereof. The views and opinions of authors expressed herein do not necessarily state or reflect those of the United States Government or any agency thereof. 


\section{DISCLAIMER}

Portions of this document may be illegible in electronic image products. Images are produced from the best available original document. 


\section{Summary}

Tank 241-SY-101 (SY-101) is a double-shell storage tank with radioactive waste that, before the recent transfer and water back dilution operations, was capable of retaining gas and producing flammable buoyant displacement (BD) gas release events (GREs). A BD GRE occurs when a portion of the nonconvective layer retains enough gas to become buoyant, rises to the waste surface, breaks up, and releases some of its stored gas. The installation of a mixer pump in 1993 successfully mitigated gas retention in the settled solids layer in SY-101 and has since prevented BD GREs. However, mixer pump operation over the years since then has caused gas retention in the floating crust layer and a corresponding accelerating waste level growth. To reverse these effects, sequences of waste removal and water back-dilution were initiated in December 1999.

In planning for these operations, there was some concern that adding the SY-101 waste into SY-102 could create a waste configuration capable of BD GREs. This report updates and extends earlier assessments of the potential for BD GRE conditions in SY-102 after waste is transferred from SY-101.

For the expected waste configuration, we determined that BD GREs will not occur in SY-102 as a result of adding the SY-101 waste during the period December 1999 through March 2000. 
0

,

!

I

I

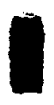

I

I

I

I

I

,

)

,

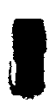

I 


\section{Contents}

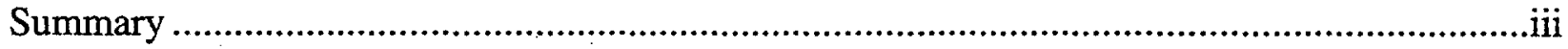

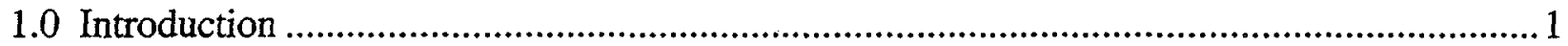

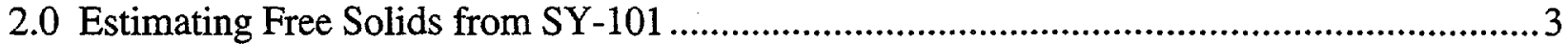

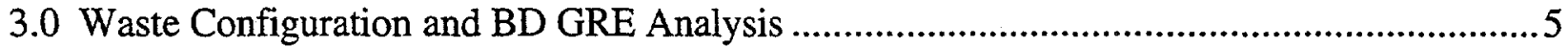

3.1 Total Mass Inventory and Waste Configuration after Transfer................................5

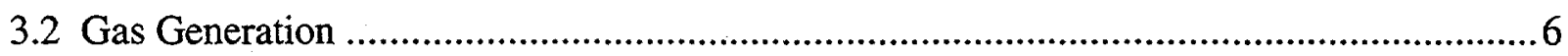

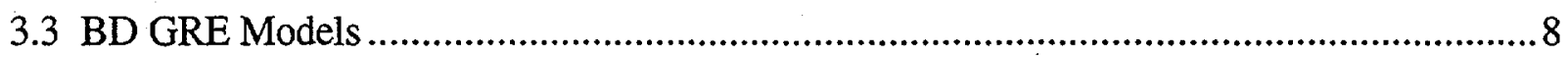

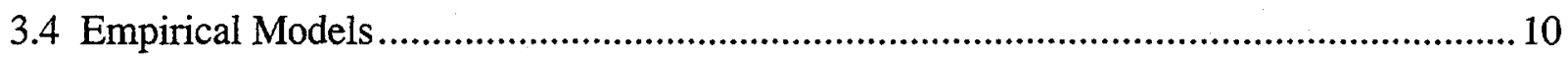

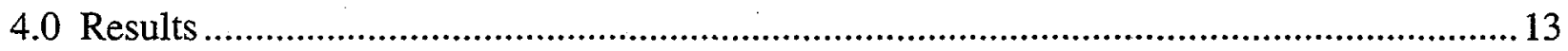

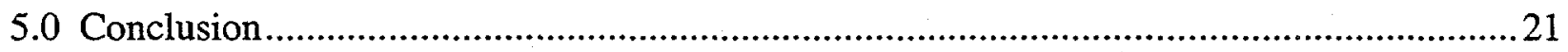

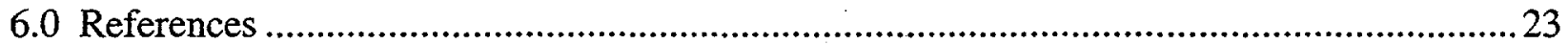

Appendix A: Development of Limit of Integration for Energy Ratio Model ........................ A.1

Appendix B: Assumptions for Model Input Parameters.................................................... B.1 


\section{Figures}

3.1 Tank SY-102 Configuration after Transfer of Diluted SY-101 Waste

4.1 Percentiles Based on Monte Carlo Simulation Results for Buoyancy Ratio (maximum dissolution)

4.2 Percentiles Based on Monte Carlo Simulation Results for $\mathrm{SpG}_{\mathrm{CL}} \mathrm{h}_{\mathrm{NCL}}$ (maximum dissolution)

4.3 Percentiles Based on Monte Carlo Simulation Results for $\mathrm{SpG}_{\mathrm{B}}$ (maximum dissolution)

4.4 Percentiles Based on Monte Carlo Simulation Results for Buoyancy Ratio (no dissolution)

4.5 Percentiles Based on Monte Carlo Simulation Results for the LFL Fraction (no dissolution)

4.6 Percentiles Based on Monte Carlo Simulation Results for $\mathrm{SpG}_{\mathrm{CL}} \mathrm{h}_{\mathrm{NCL}}$ (no dissolution)

4.7 Percentiles Based on Monte Carlo Simulation Results for $\mathrm{SpG}_{\mathrm{B}}$ (no dissolution)

\section{Tables}

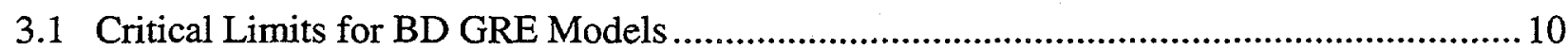

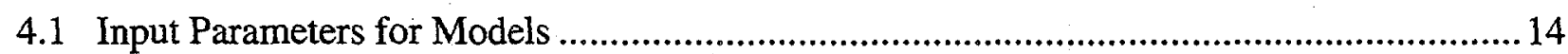

4.2 Predicted Nonconvective Layer Thickness and Neutral Buoyant Void Fraction.................. 14

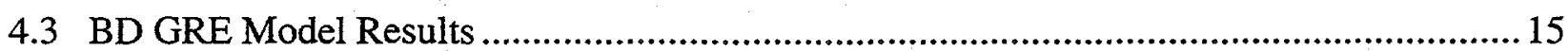




\subsection{Introduction}

Tank 241-SY-101 (SY-101) is a double-shell, radioactive waste storage tank with waste that, before the recent transfer and water back-dilution operations, was capable of retaining gas and producing buoyant displacement (BD) gas release events (GREs). Some BD GREs caused gas concentrations in the tank headspace to exceed the lower flammability limit (LFL) (Meyer et al. 1997). A BD GRE occurs when a portion of the nonconvective layer retains enough gas to become buoyant, rises to the waste surface, breaks up, and releases some of its stored gas. The installation of a mixer pump in 1993 successfully mitigated gas retention in the settled solids layer in SY-101 and has since prevented BD GREs (Allemann et al. 1994; Stewart et al. 1994; Brewster et al. 1995).

However, operation of the mixer pump over the years caused gas retention in the floating crust layer and a corresponding accelerated waste level growth. The accelerating crust growth trend observed in 1997-98 led to initiation of sequences of waste removal and water backdilutions in December 1999 (Raymond 1999; Barton 1999). Waste is removed from the mixed slurry layer in Tank SY-101 and transferred into Tank 241-SY-102 (SY-102). Water is then added back to dissolve soluble solids that retain gas. The initial transfer of 89,500 gallons of SY-101 waste, diluted in-line at $0.94: 1$ by volume with water, to SY-102 was conducted in December 1999. The second transfer of 230,000 gallons of original SY-101 waste, diluted approximately $0.9: 1$, was completed in January 2000, and the third transfer of 205,500 gallons of original SY-101 waste diluted at 0.9:1 was completed in March 2000. ${ }^{(a)}$

SY-102 also serves as a receiver tank for process water and salt-well-pumped liquid from other 200 West Area tanks (Douglas et al. 1998). The addition of the SY-101 waste into SY-102 could, in principle, increase the depth of the settled solids layer and the rate of gas generation in SY-102 to create a waste configuration that would produce BD GREs. This study analyzes the potential for BD GRE conditions in SY-102 after waste is transferred from SY-101. Results are presented based on our current understanding of the waste's behavior.

Models have been developed (Meyer et al. 1997; Meyer and Wells 2000) that indicate the behavior of BD GREs based on tank waste conditions and configuration in double-shell tanks (DSTs). The buoyancy model determines whether buoyant conditions can occur; the energy model indicates whether a buoyant displacement will be energetic enough to break up the gob and release its gas; and the release volume model estimates the volume of gas released.

These models suggest that BD GRE behavior can be characterized by macroscopic waste properties and waste layer configuration, including convective and nonconvective layer densities, layer heights, retained gas volume fraction (void fraction), pressure, yield stress, and gas

generation rate. In particular, the existence of a nonconvective layer (solid/liquid matrix) is necessary to retain gas and create BD GREs.

(a) Conner JM. February 9, 2000. Memorandum 74B50-00-009 to RE Raymond, "Tank 241-SY-101 Calculated Transfer and Dilution Volumes as of January 31, 2000." CH2MHILL, Richland, Washington. 
Empirical models have also been developed that indicate the potential for a waste tank to exhibit BD GRE behavior. These include the product of the convective layer specific gravity and the nonconvective layer depth (Estey and Guthrie 1996) and the average specific gravity of the waste (Fowler 1995).

A settled solids layer is required for BD GREs to occur. Free solids (solids that are not dissolved) can, in principle, accumulate in SY-102 by at least three mechanisms after waste is transferred from SY-101. First, free solids could be directly transported from SY-101. Second, solids could precipitate out of SY-101 waste because of cooling after transfer. Finally, if the SY-102 waste is saturated in sodium phosphate, the increase in the salt concentration caused by addition of the SY-101 waste could cause some of the phosphates to precipitate. This last effect has not yet been quantified and was not considered in this study.

A two-part approach is taken to our analysis of whether BD GREs are possible in SY-102 after waste transfer from SY-101. In Section 2, the quantity of SY-101 free solids present in SY-102 after transfer is estimated using our current knowledge of the solution chemistry and the composition of SY-101 waste. The estimated quantity of free solids is then used in Sections 3 and 4 to evaluate the potential for BD GREs under case-specific constraints using the BD GRE models. Supporting information can be found in the appendixes. 


\subsection{Estimating Free Solids from SY-101}

The amount of free solids in SY-102 after the waste is received from SY-101 depends on the effects of temperature and dilution. The temperature of the SY-101 waste is expected to be reduced by approximately $20^{\circ} \mathrm{C}$ when it is transferred into SY-102. Dilution studies conducted by Person $^{(a)}$ and Tingey et al. (1994) on samples of SY-101 waste demonstrated that dissolved solids come out of solution when undiluted waste is cooled. However, they also showed that, as the dilution was increased, the increase in free solids concentration due to lower waste temperature was reduced significantly. In fact, for dilutions greater than 30\% (0.3 parts diluent to 1 part waste), the temperature effects on solubility are negligible. This implies that the concentration of dissolved solids in the liquid remains below the saturation concentration at higher dilutions, so no new solids can be precipitated. Therefore, because the transferred waste will be diluted at ratios above $0.5: 1{ }^{(b)}$ the free solids content of the transferred SY-101 can only decrease.

A model has been developed to simulate the effects of water dilution on SY-101 waste (Rassat et al. 2000). The mass of free solids that will be dissolved for a given amount of added diluent is described in the form

$$
\Delta \mathrm{m}_{\mathrm{SD}}=\mathrm{R}_{\mathrm{D}} \mathrm{m}_{\mathrm{D}}
$$

where $R_{D}$ is the weight fraction of dissolved solids divided by the weight fraction of the water in the liquid (both prior to dilution), and $m_{D}$ is the mass of the diluent.

Waste from the mixed slurry layer of SY-101 is transferred into SY-102. This layer has a free solids weight fraction of approximately 0.23 . The SY-101 waste is diluted when it is introduced into the transfer line. The SY-101 waste and water will be fully mixed at the transfer pump, and the short transport time to SY-102 and small particle size effectively prevent particle settling in the transfer line. The transfer flow rate will be kept above the critical velocity defined by Recknagle and Onishi (1999), which ensures that the transport line flow is fully turbulent and maintains a fully mixed condition. It is therefore assumed that the SY-101 waste and diluent is fully mixed upon introduction into SY-102. However, the short transport time will minimize the amount of dissolution that may occur before the waste is actually introduced into SY-102.

In SY-102, we expect that the diluent introduced during transfer will dissolve free solids from SY-101 until it is saturated or until there are no more soluble solids available. It is possible, however, that the free solids will settle out in the tank before they are dissolved. This is highly unlikely due to the considerations discussed in the following paragraph.

The vertical temperature profiles in SY-101 indicate that after the mixer pump has excavated a volume of the settled solids in the bottom of the tank the region does not fill in for several days.

(a) Person JC. April 22, 1999. "Dilution Studies of Tank 241-SY-101 Waste. Preliminary Results." Memo 82100-99-015 to NW Kirch, Numatec Hanford Corporation, Richland, Washington.

(b) Connor JM. February 26, 1999. "Estimated Properties of Tank 241-SY-101 Waste Affecting Dilution and Transfer." Memo 74B50-99-021 to W J Powell, Lockheed Martin Hanford Corporation. 
Similarly, temperature profiles after almost a month of very severely restricted pump operations in Full-Scale Testing in 1994 showed quite limited settling (Stewart et al. 1994). From these observations it is clear that most of the disturbed solids are suspended in the liquid layer for at least several days. This suggests that the settling velocity of the suspended free solid particles is relatively slow. The dilution studies conducted by Person ${ }^{(a)}$ showed that the weight fraction of dissolved solids-at a $10 \%$ dilution with water by volume at three hours of contact time-decreased by only $5 \%$ after the sample had sat for seven days. In addition, calculations of the dissolution time of nitrate particles in water show that for even the largest particles the time of dissolution is on the order of a few hours (Stewart 1999). In conclusion, the contact time of the diluent with the SY-101 free solids after introduction into SY-102 will be sufficient to dissolve free solids until the diluent is saturated or until there are no more soluble free solids available.

The possibility of the already dilute SY-102 waste dissolving soluble solids from SY-101 has also been considered. The laboratory results of Person ${ }^{(2)}$ suggest that, when SY-102 waste is mixed with SY-101 waste that has been diluted with water, the reduction in the mixture density is due only to mixing the lower-density SY-102 waste with the diluted SY-101 waste-not to dissolution. Further, as we discuss below, the added dilution water is capable of dissolving all soluble free solids transferred from SY-101. Therefore, it is assumed there is no dissolution of SY-101 free solids into the SY-102 waste.

The mass of free solids capable of being dissolved by a given mass of diluent given by Equation (2.1) was evaluated as a function of the volume of SY-101 waste transferred. The mass of free solid that the diluent is capable of dissolving is 2.9 times greater than the mass of free solids transferred at a dilution ratio of 1:1, 2.3 times greater at a dilution ratio of $0.8: 1$, and 1.5 times greater at a dilution ratio of $0.5: 1$. These results indicate that there would be no soluble SY-101 solids left in SY-102 after the dilution. It is estimated that approximately $40 \mathrm{wt} \%$ of the free solids in SY-101 may be classified as insoluble (Kubic and Belooussov 1999; Rassat et al. 2000). ${ }^{(b)}$ Therefore, a lower limit for the amount of SY-101 free solids in SY-102 is $40 \mathrm{wt} \%$ of the transferred free solids. An extremely conservative and improbable upper limit would be to assume that no dissolution takes place, thereby maximizing the amount of SY-101 free solids transferred into SY-102.

(a) Person JC. April 22, 1999. "Dilution Studies of Tank 241-SY-101 Waste. Preliminary Results." Memo 82100-99-015 to NW Kirch, Numatec Hanford Corporation, Richland, Washington.

(b) Personal communication with WB Barton and DA Reynolds, CHGI, October 6, 1999. 


\subsection{Waste Configuration and BD GRE Analysis}

The configuration of SY-102 after receiving a transfer of SY-101 waste is determined using a balance of the total solid and liquid mass. The initial configuration of SY-102 is based on Douglas et al. (1998) and estimation of the conditions resulting from salt-well pumping from single-shell tanks at the time of SY-101 waste transfer. The liquid density is kept at or below $1350 \mathrm{~kg} / \mathrm{m}^{3}$ to satisfy waste compatibility criteria (Fowler 1999), and total waste depth in SY-102 immediately after transfer will not exceed $10.4 \mathrm{~m}^{(\mathrm{a})}$ Person $^{(\mathrm{b})}$ estimated the density of the expected SY-102 liquid composition at the time of the transfer to be approximately $1250 \mathrm{~kg} / \mathrm{m}^{3}$. Therefore $1250 \mathrm{~kg} / \mathrm{m}^{3}$ is assumed to be the initial SY-102 liquid density for this study.

The mass of the free solids and liquid of the waste transferred from SY-101 is determined from Person, ${ }^{(b)}$ Meyer et al. (1997), and Reynolds (1993). Based on these references and the slurry density given in Stewart et al. (1996), the transferred SY-101 waste has a free solids volume fraction of approximately 0.16 ( $23 \%$ by mass). The waste is diluted with water during the transfer. As discussed above, the dilution ratio (volume of dilution water to volume of waste) during the transfer will preclude the effect of the temperature change on the soluble solid content, and the diluent will be capable of dissolving all of the soluble solids. The dilution ratio is assumed to be $0.9: 1$ for this study. This assumption closely matches the actual dilution for the transfers (see Section 1).

It is further assumed that the existing nonconvective layer in SY-102 will not participate in a $\mathrm{BD}$ and may be treated as a stationary layer. However, the gas generation from this layer will contribute to the total gas generation rate in the tank after the SY-101 waste is added.

\subsection{Total Mass Inventory and Waste Configuration after Transfer}

We assume that the arrangement of the total inventory of the free solids and liquid in SY-102 after the waste is received from SY-101 is as described in this section. The final tank configuration is pictured in Figure 3.1.

The liquid layer is conservatively assumed to contain no free solids. The possibility for stratification of the liquid has been considered but is deemed improbable. TEMPEST code simulations show that, after one hour of transfer of diluted SY-101 waste into SY-102 at $140 \mathrm{gpm}$, the concentration of SY-101 free solids at the surface of the waste is approximately 20 times less than on top of the stationary layer $\left(a 10^{-9} \mathrm{~m} / \mathrm{s}\right.$ settling rate was assumed). ${ }^{(c)}$ The identification of SY-101 free solids throughout the tank, coupled with the extremely slow settling rate that precludes any settling during the simulation, indicates that mixing is occurring, although it may not be complete. However, it is highly likely that the SY-101 diluted waste will be less

(a) Personal communication with WB Barton and DA Reynolds, CHGI, October 6, 1999.

(b) Person JC. April 22, 1999. "Dilution Studies of Tank 241-SY-101 Waste. Preliminary Results." Memo 82100-99-015 to NW Kirch, Numatec Hanford Corporation, Richland, Washington.

(c) Personal communication with Y Onishi, Pacific Northwest National Laboratory, October 6, 1999. 


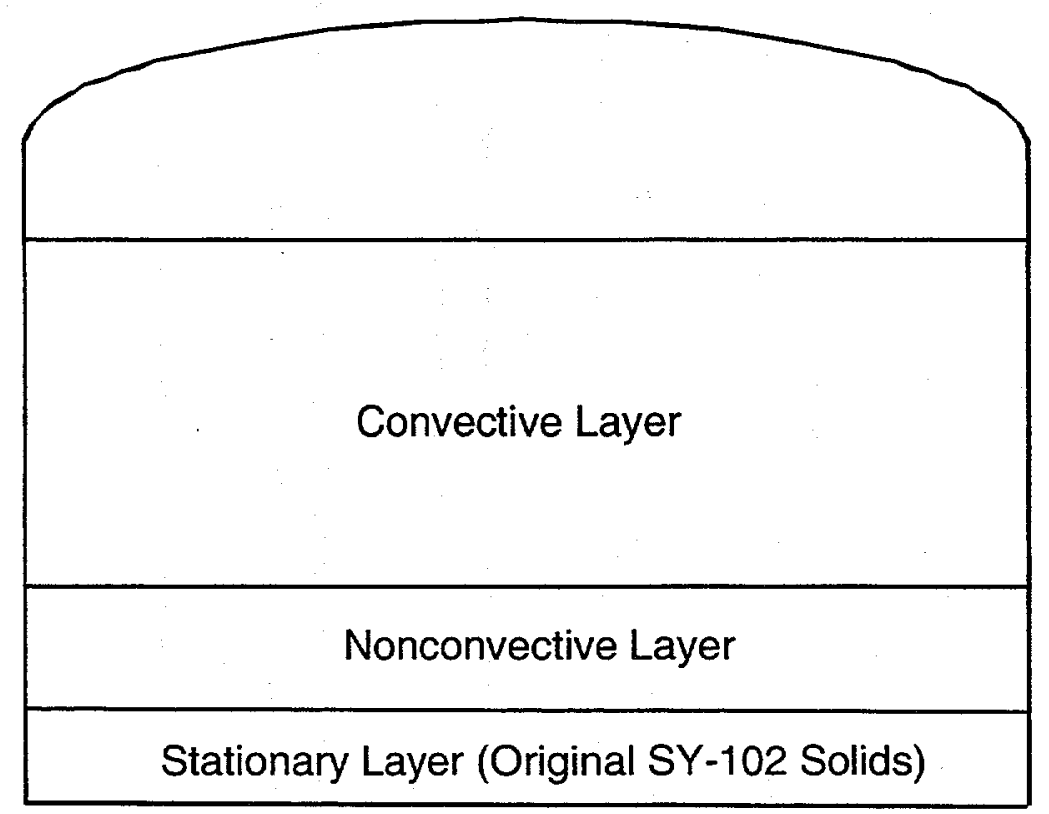

Figure 3.1. Tank SY-102 Configuration after Transfer of Diluted SY-101 Waste

dense than the SY-102 liquid after the free solids have settled out (both with and without dissolution), and the liquid layer will then become well mixed due to buoyant effects. Therefore, existence of a stratified waste configuration in the long term is deemed highly unlikely and will not be evaluated.

All of the free solids in the tank are assumed to settle out into the nonconvective layer. It may be argued that, in the time required to form BD GRE conditions in the tank, the material will have settled to a state much like the pre-mixer-pump configuration of SY-101. The volumetric solids fraction of the nonconvective layer is therefore assumed to be that of the premixer pump SY-101 nonconvective layer (i. e:, no "fluffing").

Two assumptions must be emphasized at this point. First, it is assumed there is no dissolution of SY-101 free solids into the SY-102 waste. Therefore, the density of the mixed convective layer is computed simply by volumetric mixing as indicated by Person. ${ }^{(a)}$ Second, it is assumed there is no precipitation of free solids from the SY-102 liquid.

\subsection{Gas Generation}

The gas generation in SY-102 after addition of SY-101 waste is an integral part of the BD GRE investigation. The volumetric gas generation rate per nonconvective layer volume includes the gas generated in the stationary layer below and is estimated as

(a) Person JC. April 22, 1999. "Dilution Studies of Tank 241-SY-101 Waste. Preliminary Results." Memo 82100-99-015 to NW Kirch, Numatec Hanford Corporation, Richland, Washington. 


$$
\dot{\mathrm{g}}_{\mathrm{NCL}}=\dot{\mathrm{g}}_{\mathrm{m}}+\frac{\dot{\mathrm{G}}_{102}^{\prime}}{\mathrm{V}_{\mathrm{NCL}}\left[\mathrm{H}_{2}\right]_{102}}
$$

where $\mathrm{V}_{\mathrm{NCL}}$ is the volume of the nonconvective layer formed above the stationary layer, $\dot{\mathrm{G}}_{102}^{\prime}$ is the hydrogen volumetric generation rate in SY-102 $\left(\mathrm{m}^{3} /\right.$ day), $\left[\mathrm{H}_{2}\right]_{102}$ is the hydrogen fraction of the gas generated in SY-102, and $\dot{\mathrm{g}}_{\mathrm{m}}$ is the volumetric gas generation of the SY-101 waste after it is diluted and mixed with the SY-102 waste, given by

$$
\dot{\mathrm{g}}_{\mathrm{m}}=\frac{\dot{\mathrm{g}}_{101} \mathrm{~V}_{\mathrm{tr}}}{\mathrm{V}_{\mathrm{tr}}+\mathrm{V}_{\mathrm{dil}}+\mathrm{V}_{102}}
$$

where $\dot{\mathrm{g}}_{101}$ is the total volumetric gas generation rate of $\mathrm{SY}-101\left(\mathrm{~m}^{3} / \mathrm{m}^{3}\right.$-day), $\mathrm{V}_{\mathrm{tr}}$ and $\mathrm{V}_{\mathrm{dil}}$, are the volumes of the SY-101 waste transfer and diluent added, respectively, and $\mathrm{V}_{102}$ is the volume of SY-102 waste above the stationary layer. The molar gas generation rate in SY-102 after transfer is therefore given by

$$
\dot{\mathrm{n}}_{\mathrm{tot}}=\left[\frac{\dot{\mathrm{g}}_{101} \mathrm{~V}_{\mathrm{tr}}}{\mathrm{V}_{\mathrm{tr}}+\mathrm{V}_{\mathrm{dil}}+\mathrm{V}_{102}}+\frac{\dot{\mathrm{G}}_{102}^{\prime}}{\mathrm{V}_{\mathrm{NCL}}\left[\mathrm{H}_{2}\right]_{102}}\right] \frac{\mathrm{P}}{\mathrm{RT}}
$$

where $P$ is the standard atmospheric pressure, $R$ is the universal gas constant, and $T$ is the standard temperature. (Values and data sources for these parameters are given in Table 4.1.)

Equation (3.3) has been compared with the models in $\mathrm{Hu}$ (1999), in which empirical rate equations were derived to estimate hydrogen generation. The hydrogen generation rate of the SY-101 waste diluted approximately $1: 1$ by volume with water was computed using these equations with the chemical constituent data from the dilution studies of Person. ${ }^{(a)}$ The results indicate a decrease of approximately $88 \%$ in the hydrogen generation rate compared with the $60 \%$ decrease determined from Equation (3.3). Therefore, the results of Equation (3.3) are conservative.

The hydrogen fraction in the gas generated in SY-102 will almost certainly be higher than in SY-101. Both the soluble organic concentration and the temperature will be lower, which suggests that radiolysis of water may be more important in gas generation than the thermal reaction. Because the majority of the nitrogenous gases are generated by the oxidative degeneration of the complexant HEDTA, and radiolysis produces hydrogen, the hydrogen concentration of the generated gas will be higher relative to the other gases (Hu 1999). Mahoney et al. (1999) found that the maximum hydrogen concentration in DSTs was approximately 0.65 (Tank AN-105). We assume a conservative hydrogen concentration of 0.75 in the gas generated in SY-102 for this study.

(a) Person JC. April 22, 1999. "Dilution Studies of Tank 241-SY-101 Waste. Preliminary Results." Memo 82100-99-015 to NW Kirch, Numatec Hanford Corporation, Richland, Washington. 


\subsection{BD GRE Models}

The possibility for BD GREs in SY-102 after the addition of SY-101 waste is evaluated using the gas release, energy, and buoyancy models. The gas release model, which estimates the volume of the gas released in a BD GRE, is used to determine whether the tank is capable of producing a GRE that would exceed the LFL. A simplified model is presented in Meyer et al. (1997) and Meyer and Wells (2000). It gives the volume of gas release as

$$
V_{\text {rel }}=C\left(P_{s}-1\right) \alpha_{N B} h_{N C L}\left(\tau_{y} / \rho_{C L}\right)
$$

where $\tau_{\mathrm{y}}$ is the average yield stress in shear, and $\rho_{\mathrm{CL}}$ is the convective layer density. The average pressure of the gas in the nonconvective layer is given by

$$
\mathrm{P}_{\mathrm{s}}=1+\frac{\rho_{\mathrm{CL}} \mathrm{g}}{\mathrm{P}_{\mathrm{A}}}\left(\mathrm{h}_{\mathrm{C}}+\mathrm{h}_{\mathrm{CL}}+\frac{\mathrm{h}_{\mathrm{NCL}}}{2}\right)
$$

with $\mathrm{P}_{\mathrm{A}}$ equal to the atmospheric pressure, and $\mathrm{g}$ equal to the acceleration due to gravity. The thickness of the crust, convective layer, and nonconvective layer are denoted by $h_{C}, h_{\mathrm{CL}}$, and $h_{\mathrm{NCL}}$, respectively. $\alpha_{N B}$ is the neutral buoyancy void fraction defined by

$$
\alpha_{\mathrm{NB}}=1-\frac{\rho_{\mathrm{CL}}}{\rho_{\mathrm{NCL}}}
$$

The leading coefficient of Equation (3.5), $\mathrm{C}$, is adjusted so the release volume matches historical BD GRE data. The release volume model results have been compared with the average historical BD GRE release volumes for DSTs AN-103, AN-104, AN-105, AW-101, SY-103, and SY-101 (Meyer et al. 1997; Meyer and Wells 2000). Gas release volumes for BD GREs in SY-101 are underestimated when the constant is adjusted to match the historical data of these other tanks. This has been attributed to multi-gob participation in BD GREs in SY-101, as evidenced by in-tank video taken during the events. This unique behavior in SY-101 is attributed in part to its relatively high gas-generation rate. As we discuss, the dilution and addition of the SY-101 waste to SY-102 reduce the gas generation rate, thereby reducing the rate at which a gob can be rendered buoyant. In fact, the gas generation rate is estimated to approach those of the other five tanks. This effect suggests that it would be plausible to use the coefficient determined by comparing the model with BD GREs in tanks other than SY-101. Accordingly, a value of $\mathrm{C}=403$ has been calculated and is used for this study.

Assuming instantaneous release and a well-mixed headspace, the LFL fraction can be determined by

LFL fraction $=\frac{\left(\frac{\mathrm{V}_{\mathrm{rel}}\left[\mathrm{H}_{2}\right]}{\mathrm{V}_{\mathrm{h}}}\right)}{\mathrm{LFL}_{\mathrm{H}_{2}}}$ 
where $\left[\mathrm{H}_{2}\right]$ is the average hydrogen concentration of the gas released $(0.75), V_{h}$ is the headspace volume of the tank, and $\mathrm{LFL}_{\mathrm{H} 2}$ is the LFL of hydrogen. In SY-101, with ammonia concentraions of 10 to $12 \%$ in the retained gas (Mahoney et al. 1999), $\mathrm{LFL}_{\mathrm{H} 2}$ can be determined with Le Chatlier's principle to be 0.036 . However, the increased hydrogen concentration in the retained gas in SY-102, coupled with the expected decrease in ammonia concentration (due to the dilution of the SY-101 waste with water and the SY-102 liquid), $L F L_{\mathrm{H} 2}$ is assumed to be 0.04 for this study.

The energy model is used to determine whether the buoyant material will yield and release the retained gas. The model is defined as the ratio between the buoyant potential energy and the energy required to yield the gas-bearing gob participating in the buoyant displacement (Meyer et al. 1997; Meyer and Wells 2000). The energy ratio is computed by

$$
\frac{\mathrm{E}_{\mathrm{b}}}{\mathrm{E}_{\mathrm{y}}}=\frac{\alpha_{\mathrm{o}} \rho_{\mathrm{CL}} \mathrm{gh}}{\left(1-\alpha_{\mathrm{o}}\right) \varepsilon_{\mathrm{y}} \tau_{\mathrm{y}}}\left[\left(1+\frac{1}{\gamma}\right) \ln (1+\gamma)-\mathrm{k}\right]
$$

where $\alpha_{0}$ is the initial void fraction of the waste, $\varepsilon_{\mathrm{y}}$ is the strain at failure, and $\mathrm{h}$ is the distance from the center of the participating gob to the top of the liquid layer as it exists after the gob rises. This is defined with the aid of a buoyancy model as

$$
\mathrm{h}=\mathrm{h}_{\mathrm{CL}}+\mathrm{h}_{\mathrm{NCL}}\left\{\frac{1}{2}+\frac{1}{2}\left[\mathrm{p}_{\mathrm{S}} \alpha_{0}+\left(1-\alpha_{0}\right)\right]^{\frac{1}{3}}-\frac{\rho_{\mathrm{NCL}}}{\rho_{\mathrm{L}}}\left(1-\alpha_{0}\right)\left[\mathrm{p}_{\mathrm{S}} \alpha_{0}+\left(1-\alpha_{0}\right)\right]^{-\frac{2}{3}}\right\}
$$

where $\alpha_{0}$ is the initial void fraction. The development of Equation (3.9) is included in Appendix A. For this study, the initial void fraction is taken to be the critical void fraction defined by

$$
\alpha_{C}=\alpha_{\mathrm{NB}}+\frac{\beta \tau_{\mathrm{y}}}{\rho_{\mathrm{NCL}} g h_{\mathrm{NCL}}}
$$

The waste material may yield in a combination of tension and shear. The Mises yield condition implies that the yield stress in tension is $\sqrt{3}$ times the yield stress in pure shear. Therefore, the stress at yielding may be given by $\beta \tau_{y}$, where $1 \leq \beta \leq \sqrt{3} . \beta=1$ will be used in this study because the results of Meyer et al. (1997) indicate that this provides good correlation between measured and calculated void data for the DSTs listed above. The parameter $\gamma$ is determined from

$$
\gamma=\frac{\rho_{\mathrm{CL}} \mathrm{gh}}{\mathrm{P}_{\mathrm{A}}}
$$

and the parameter $\mathrm{k}$ from

$$
k=\frac{\alpha_{\mathrm{NB}}\left(1-\alpha_{\mathrm{o}}\right)}{\alpha_{\mathrm{o}}\left(1-\alpha_{\mathrm{NB}}\right)}
$$


Observations of the six DSTs exhibiting BD GRE behavior and scaled experiment results indicate the following criteria: no disruptive buoyant displacement is expected for $E_{b} / E_{y}<1$, buoyant displacements with limited gas release might occur for $\mathrm{E}_{\mathrm{b}} / \mathrm{E}_{\mathrm{y}}>\sim 4$, and major gas releases can be expected if $E_{b} / E_{y}>\sim 6$ (Meyer et al. 1997; Meyer and Wells 2000). The conservative limit of 4 is chosen for this study.

The buoyancy model is used to determine whether a gob of the nonconvective layer may become buoyant. The maximum void fraction is given by Meyer and Wells (2000) as

$$
\alpha_{\max }=C_{\mathrm{BM}}\left(\frac{\dot{\mathrm{n}} \mathrm{T}_{\mathrm{w}}}{\mathrm{P}_{\mathrm{s}}}\right)^{\frac{1}{3}}\left(\frac{\mathrm{h}_{\mathrm{NCL}}{ }^{2}}{\rho_{\mathrm{NCL}}}\right)
$$

where $\mathrm{C}_{\mathrm{BM}}$ is a constant adjusted so that the minimum buoyancy ratio for the DSTs historically exhibiting BD GRE behavior (AN-103, AN-104, AN-105, AW-101, SY-103, and SY-101) is $1.0, \dot{n}$ is the molar gas generation rate in the tank given by Equation (3.3), and $T_{w}$ is the waste temperature. Buoyancy occurs when the average void fraction is equal to the neutral buoyant void fraction. The ratio of the two void fractions, or the buoyancy ratio, is unity at this point. The average void fraction is three-fourths of the maximum void fraction, and the buoyancy ratio is given by

$$
\mathrm{BR}=0.75 \frac{\alpha_{\max }}{\alpha_{\mathrm{NB}}}
$$

The critical limits for the BD GRE models are listed in Table 3.1. Below these values a BD GRE is no longer possible or will not be flammable.

Table 3.1. Critical Limits for BD GRE Models

\begin{tabular}{|c|c|}
\hline Model & Critical Limit \\
\hline LFL Fraction (from gas release) & 1.0 \\
\hline Energy Ratio & 4.0 \\
\hline Buoyancy Ratio & 1.0 \\
\hline
\end{tabular}

\subsection{Empirical Models}

The empirical models of Estey and Guthrie (1996) and Fowler (1995) are also evaluated to consider the possibility for BD GREs in SY-102 after the addition of SY-101 waste.

The product of the convective layer specific gravity and the nonconvective layer depth (Estey and Guthrie 1996) is computed from

$$
\mathrm{SpG}_{\mathrm{CL}} \mathrm{h}_{\mathrm{NCL}}=\frac{\rho_{\mathrm{CL}}}{1000} \mathrm{~h}_{\mathrm{NCL}}
$$


where, in this case, the thickness of the nonconvective layer has units of inches. The limit of 150 in. was determined to conservatively separate BD GRE tanks from non-BD GRE tanks.

The average specific gravity of the waste (Fowler 1995) is determined volumetrically by

$$
\mathrm{SpG}_{\mathrm{B}}=\frac{\frac{\rho_{\mathrm{CL}}}{1000} \mathrm{~h}_{\mathrm{CL}}+\frac{\rho_{\mathrm{NCL}}}{1000} \mathrm{~h}_{\mathrm{NCL}}\left(1-\alpha_{\mathrm{NCL}}\right)+\frac{\rho_{\text {stat }}}{1000} \mathrm{~h}_{\text {stat }}}{\mathrm{h}_{\mathrm{CL}}+\mathrm{h}_{\mathrm{NCL}}\left(1-\alpha_{\mathrm{NCL}}\right)+\mathrm{h}_{\text {stat }}}
$$

where $\alpha_{\text {NCL }}$ is the void fraction of the nonconvective layer, and $\rho_{\text {stat }}$ and $h_{\text {stat }}$ are the density and thickness of the stationary layer in SY-102, respectively. The limiting average specific gravity is given as 1.35 , but 1.41 is deemed a better estimate. ${ }^{(a)}$

(a) Personal communication from DA Reynolds, CHGI, to CW Stewart, PNNL. 


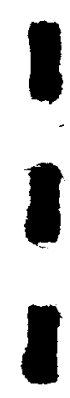

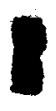

I

I

】

I

I

I

I

I

I

I

I

I

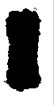

8 


\subsection{Results}

The initial transfer in December 1999 introduced 89,500 gallons of SY-101 waste into SY-102. A second transfer moved another 230,000 gallons of SY-101 waste into SY-102 in January 2000. The third transfer of an additional 205,500 gallons (equivalent undiluted waste) was completed in March 2000. The cumulative addition of SY-101 waste into SY-102 then is 525,000 gallons, with 472,500 gallons of dilution water added back.

During the interval between the transfers, SY-102 continued to serve in its capacity as a receiver tank for process water and salt-well-pumped supernatant liquid from other 200 West Area tanks. The state of SY-102 receiving the subsequent transfers has been assumed based on the final waste level and density in SY-102 being kept within the limits specified in Section 3. The current Authorization Basis for a cross-site transfer out of SY-102 limits the free solids to less than $5 \%$ by volume in the transfer line, and the transfer pump itself (it is a flex and float pump; the inlet is kept at the waste surface) is not designed to remove solids from the tank. ${ }^{\text {(a) }}$ It is therefore assumed that no free solids will be removed in the cross-site transfers. The model input parameters are given in Table 4.1 .

As discussed in Section 3.3, a settled solids layer is required to retain gas and create BD GREs. The BD GRE models reflect this. The estimated steady state nonconvective layer thickness and neutral buoyant void fraction in SY-102 after the diluted SY-101 waste was added are given in Table 4.2 .

The BD GRE and empirical model results for the estimated steady-state waste configuration in SY-102 after addition of diluted SY-101 waste are presented in Table 4.3. The uncertainty ranges shown in the table represent a $95 \%$ confidence interval around the mean. The uncertainties were derived with a Monte Carlo simulation based on uncertainty distributions assumed for each of the input parameters. These are listed in Appendix B.

For maximum dissolution, the buoyancy ratio does not exceed 1.0 in the $95 \%$ confidence interval, precluding the possibility of a BD GRE. In fact, in the $99.5 \%$ confidence interval, the buoyancy ratio does not exceed 0.5 (see Figure 4.1). The empirical models also indicate that BD GREs will not occur within the $95 \%$ confidence interval. The product of the specific gravity of the convective layer and the nonconvective layer depth does not approach within $33 \%$ of its limit in the $99.5 \%$ confidence interval, while the average specific gravity just achieves its limit (see Figures 4.2 and 4.3). Because no BD GREs can occur, the other models do not apply. Their results are shown for information only.

For the improbable case of no dissolution, BD GREs were determined to be possible within the $95 \%$ confidence interval. Approximately $25 \%$ of the Monte Carlo simulations gave a buoyancy ratio greater than 1.0 (Figure 4.4). Nevertheless, the headspace hydrogen concentration resulting from one of these BD GREs is always below the LFL (Figure 4.5). The product of the convective layer specific gravity and the nonconvective layer depth also indicates the possibility

(a) Personal communication with MJ Sutey, CHGI, October 11, 1999. 
Table 4.1. Input Parameters for Models

\begin{tabular}{|c|c|c|}
\hline \multicolumn{3}{|c|}{ Transferred SY-101 Waste } \\
\hline Property & Value and Units & Source \\
\hline Liquid Density & $1490 \mathrm{~kg} / \mathrm{m}^{3}$ & Rassat et al. (2000) \\
\hline Free Solid Density & $2200 \mathrm{~kg} / \mathrm{m}^{3}$ & Rassat et al. (2000) \\
\hline $\begin{array}{l}\text { Ratio of Solids to Water Mass at } \\
\text { Saturation at } 50^{\circ} \mathrm{C}\end{array}$ & 1.267 & Rassat et al. (2000) \\
\hline Fraction of Solids Dissolved by Dilution & 0.60 & Rassat et al. (2000) \\
\hline $\begin{array}{l}\text { Free Solid Volume Fraction in Waste } \\
\text { Transferred from SY-101 }\end{array}$ & 0.16 & (a) \\
\hline Volumetric Gas Generation Rate & $7.56 \mathrm{E}-4 \mathrm{~m}^{3} / \mathrm{m}^{3}$-day & (b) \\
\hline Waste Temperature & $323 \mathrm{~K}$ & DACS \\
\hline $\begin{array}{l}\text { Free Solid Volume Fraction of Settled } \\
\text { SY-101 Solids in SY-102 }\end{array}$ & 0.30 & (c) \\
\hline $\begin{array}{l}\text { Gas Fraction in Settled SY-101 Solids } \\
\text { Layer in SY-102 }\end{array}$ & 0.08 & (c) \\
\hline $\begin{array}{l}\text { Yield Stress in Shear of Settled SY-101 } \\
\text { Solids Layer in SY-102 }\end{array}$ & $116 \mathrm{~Pa}$ & (c) \\
\hline \multicolumn{3}{|l|}{ SY-102 } \\
\hline Property & Value and Units & Source \\
\hline Stationary Layer Thickness & $0.65 \mathrm{~m}$ & Douglas et al. (1998) \\
\hline Stationary Layer Density & $1550 \mathrm{~kg} / \mathrm{m}^{3}$ & Douglas et al. (1998) \\
\hline Supernatant Liquid Density & $1250 \mathrm{~kg} / \mathrm{m}^{3}$ & Person $^{(\mathrm{d})}$ \\
\hline $\mathrm{H}_{2}$ Generation Rate & $0.03 \mathrm{~m}^{3} /$ day & McCain (1999) \\
\hline $\mathrm{H}_{2}$ Mole Fraction in Waste & 0.65 & (e) \\
\hline Waste Temperature & $301 \mathrm{~K}$ & SACS \\
\hline \multicolumn{3}{|c|}{$\begin{array}{l}\text { (a) Computed from ball theometer slurry layer density data }\left(1600 \mathrm{~kg} / \mathrm{m}^{3} \text { ) (Stewart et al. 1996). }\right. \\
\text { (b) Computed based on total gas generation of } 109 \mathrm{ft}^{3} / \mathrm{day} \text {. } \\
\text { (d) Assumed from historical SY-101 data (Meyer et al. 1997; Reynolds 1993). } \\
\text { (d) Person JC. April 22, 1999. "Dilution Studies of Tank 241-SY-101 Waste. Preliminary Results." Memo } \\
82100-99-015 \text { to NW Kirch, Numatec Hanford Corporation, Richland, Washington. }\end{array}$} \\
\hline
\end{tabular}

Table 4.2. Predicted Nonconvective Layer Thickness and Neutral Buoyant Void Fraction

\begin{tabular}{|l|c|c|}
\hline Case & $\mathbf{h}_{\mathrm{NCL}}$ (in.) & $\alpha_{\mathrm{NB}}$ \\
\hline Maximum & 44.2 & 0.17 \\
Dissolution & $-36+18$ & \pm 0.04 \\
\hline No Dissolution & 110.5 & 0.19 \\
& $-76+86$ & \pm 0.04 \\
\hline
\end{tabular}


Table 4.3. BD GRE Model Results

\begin{tabular}{|c|c|c|c|c|}
\hline Case & BD GRE Models & Result & $\begin{array}{l}\text { Empirical } \\
\text { Models }\end{array}$ & Result \\
\hline \multirow[t]{3}{*}{$\begin{array}{c}\text { Maximum } \\
\text { Dissolution }\end{array}$} & Buoyancy Ratio & $\begin{array}{c}0.13 \\
-0.12+0.16 \\
\end{array}$ & $\mathrm{SpG}_{\mathrm{CL}} \mathrm{h}_{\mathrm{NCL}}$ & $\begin{array}{l}58 \text { (in.) } \\
-47+25 \\
\end{array}$ \\
\hline & Energy Ratio & $\begin{array}{c}95^{\text {(a) }} \\
-33+118\end{array}$ & \multirow[t]{2}{*}{$\overline{\mathrm{SpG}_{\mathrm{B}}}$} & \multirow[t]{2}{*}{$\begin{array}{c}1.35 \\
\pm 0.05\end{array}$} \\
\hline & LFL Fraction & $\begin{array}{c}0.13^{(2)} \\
-0.11+0.05\end{array}$ & & \\
\hline \multirow[t]{3}{*}{$\begin{array}{c}\text { No } \\
\text { Dissolution }\end{array}$} & Buoyancy Ratio & $\begin{array}{c}0.72 \\
-0.62+1.84\end{array}$ & $\mathrm{SpG}_{\mathrm{CL}} \mathbf{h}_{\mathrm{NCL}}$ & $\begin{array}{l}136 \text { (in.) } \\
-92+99\end{array}$ \\
\hline & Energy Ratio & $\begin{array}{c}71 \\
-40+68\end{array}$ & \multirow[t]{2}{*}{$\overline{\mathrm{SpG}}$} & \multirow[t]{2}{*}{$\begin{array}{c}1.33 \\
\pm 0.02\end{array}$} \\
\hline & LFL Fraction & $\begin{array}{c}0.40 \\
-0.30+0.34\end{array}$ & & \\
\hline
\end{tabular}

of BD GREs within the $95 \%$ confidence interval, although the average specific gravity of the waste does not exceed its limit in the $99.5 \%$ confidence interval (Figures 4.6 and 4.7 ).

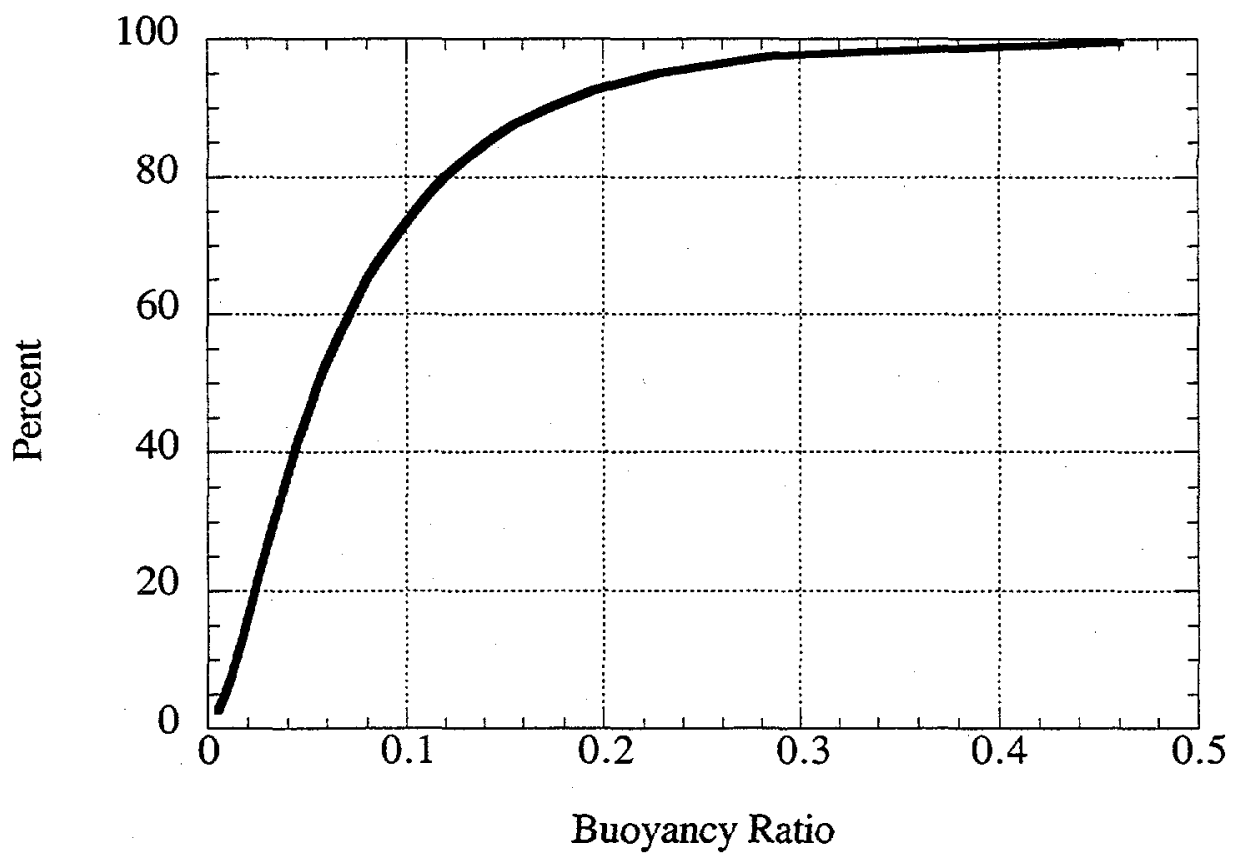

Figure 4.1. Percentiles Based on Monte Carlo Simulation Results for the Buoyancy Ratio (maximum dissolution) 


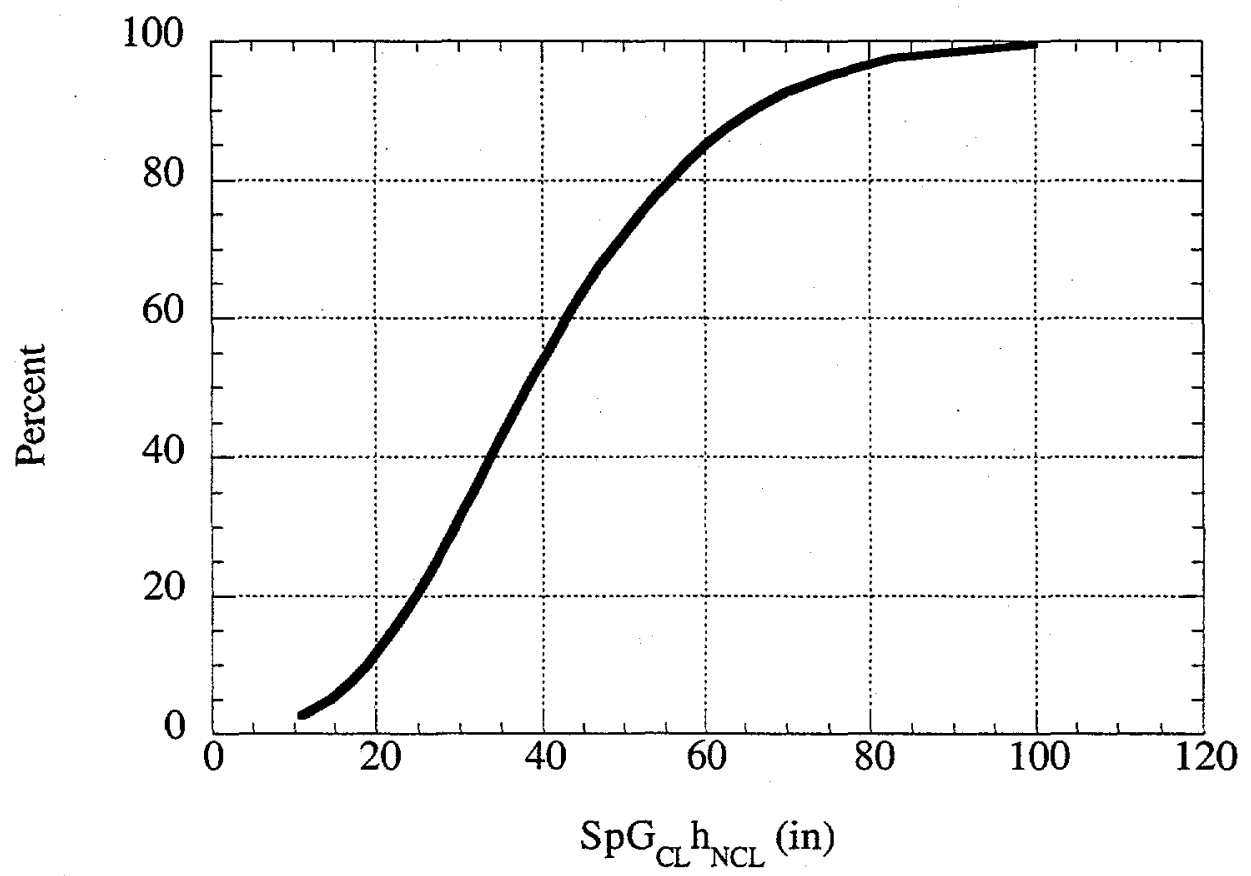

Figure 4.2. Percentiles Based on Monte Carlo Simulation Results for $\mathrm{SpG}_{\mathrm{CL}} \mathrm{h}_{\mathrm{NCL}}$ (maximum dissolution)

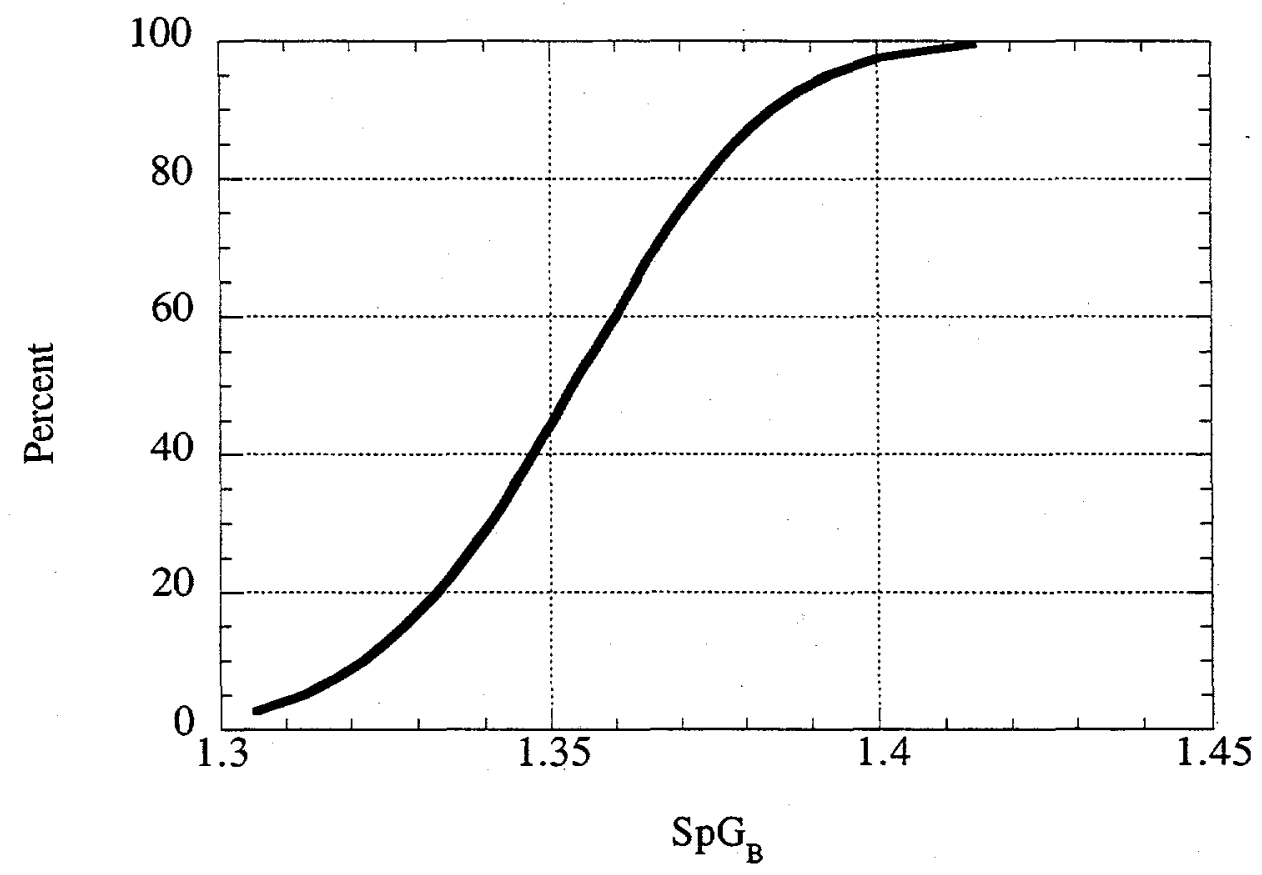

Figure 4.3. Percentiles Based on Monte Carlo Simulation Results for $\mathrm{SpG}_{\mathrm{B}}$ (maximum dissolution) 


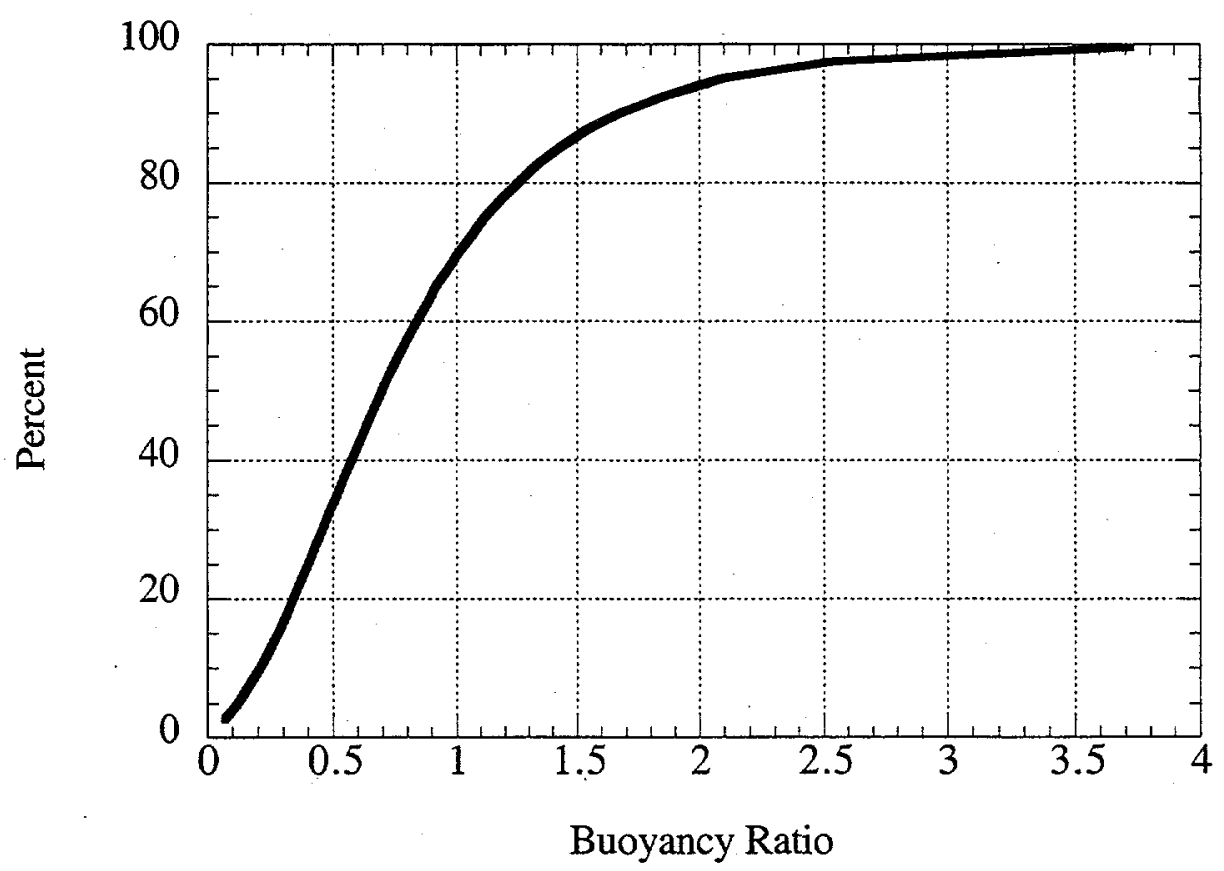

Figure 4.4. Percentiles Based on Monte Carlo Simulation Results for the Buoyancy Ratio (no dissolution)

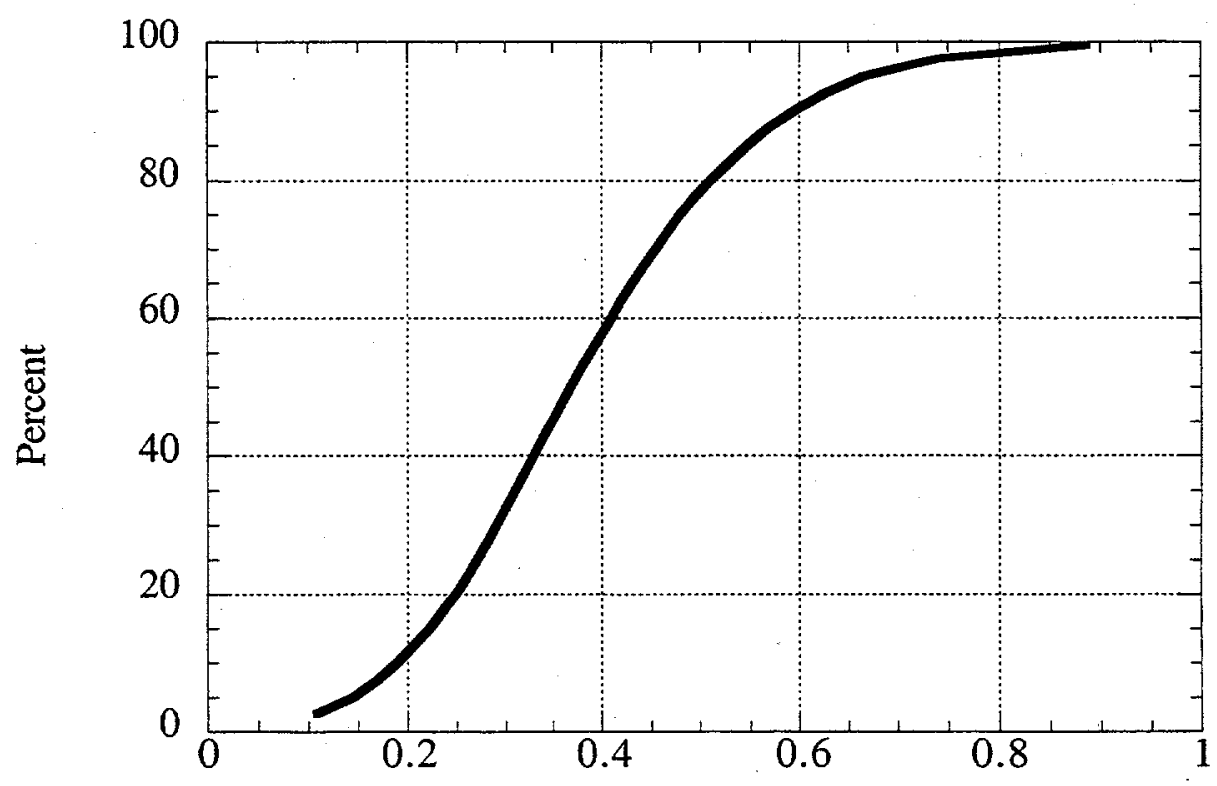

LFL Fraction

Figure 4.5. Percentiles Based on Monte Carlo Simulation Results for the LFL Fraction (no dissolution) 


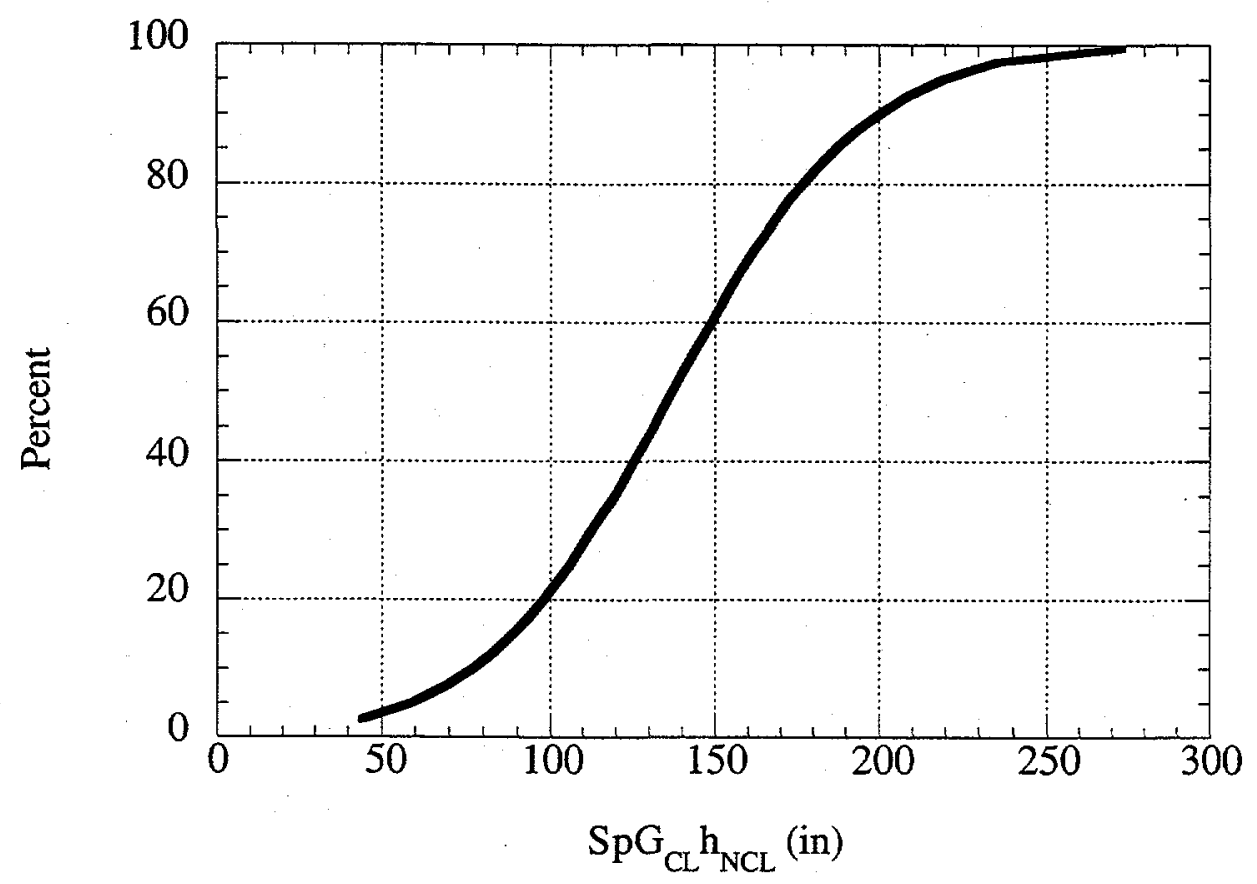

Figure 4.6. Percentiles Based on Monte Carlo Simulation Results for $\mathrm{SpG}_{\mathrm{CL}} \mathrm{h}_{\mathrm{NCL}}$ (no dissolution)

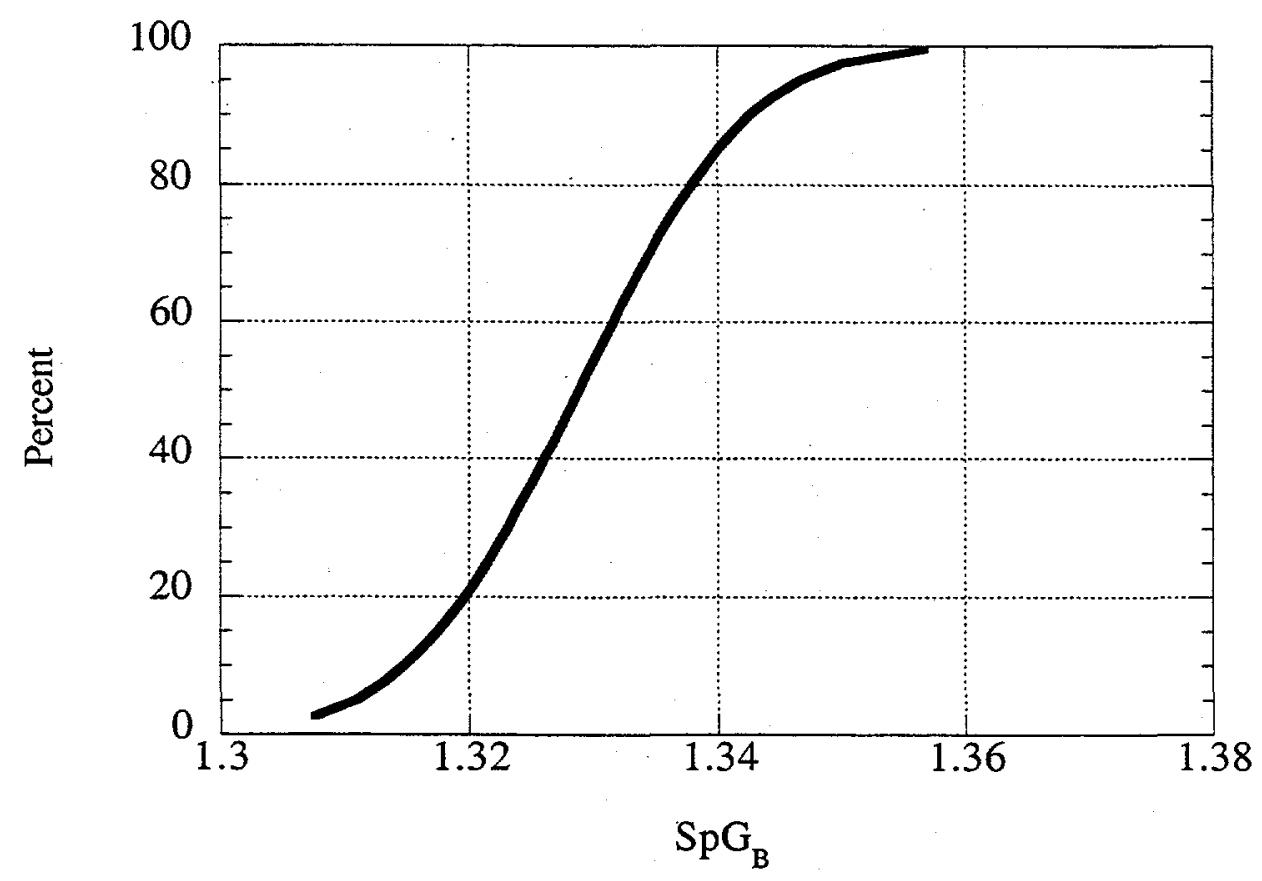

Figure 4.7. Percentiles Based on Monte Carlo Simulation Results for $\mathrm{SpG}_{\mathrm{B}}$ (no dissolution) 
If the stated assumptions (i.e., no dissolution of SY-101 free solids into the SY-102 waste, no precipitation of free solids from the SY-102 liquid, the volumetric solids fraction of the nonconvective layer is that of the pre-mixer pump SY-101 nonconvective layer) are altered to include, for example, the precipitation of phosphates from the SY-102 liquid, a sensitivity analysis of these results shows that buoyant conditions can also occur (although the subsequent gas release is far below the LFL), and the product of the convective layer specific gravity and the nonconvective layer depth can also exceed its limit. 


\subsection{Conclusion}

The results of the BD GRE and empirical models indicate that, after the transfer of 525,000 gallons of waste from Tank SY-101 diluted with water at 0.9:1 into Tank SY-102, BD GREs will not occur in SY-102 under the given assumptions and allowing for dissolution of soluble solids to occur as expected. However, under the conservative assumption that no dissolution occurs, or if a large volume of phosphate precipitation is assumed in SY-102, BD GREs are indicated to be possible, though not flammable. 


\subsection{References}

Allemann RT, ZI Antoniak, WD Chvala, LE Efferding, JR Friley, WB Gregory, JD Hudson, JJ Irwin, NW Kirch, TE Michener, FE Panisko, CW Stewart, and BM Wise. 1994. Mitigation of Tank 241-SY-101 by Pump Mixing: Results of Testing Phases $A$ and B. PNL-9423, Pacific Northwest National Laboratory, Richland, Washington.

Barton WB. 1999. Maximum First Transfer and Dilution Volumes for 241-SY-101. RPP-5344 Rev. 0, Lockheed Martin Hanford Corp., Richland, Washington.

Brewster ME, NB Gallagher, JD Hudson, and CW Stewart. 1995. The Behavior, Quantity, and Location of Undissolved Gas in Tank 241-SY-101. PNL-10681, Pacific Northwest National Laboratory, Richland, Washington.

Douglas JG, LJ Fergestrom, and SR Wilmarth. 1998. Tank Characterization Report for DoubleShell Tank 241-SY-102. HNF-SD-WM-ER-366 Rev. 1, Fluor Daniel Hanford Inc., Richland, Washington.

Estey SD and MD Guthrie. 1996. An Analysis of Parameters Describing Gas Retention/Release Behavior in Double-Shell Tank Waste. WHC-SD-WM-TI-755. Westinghouse Hanford Co., Richland, Washington.

Fowler KD. 1999. Tank Farm Waste Transfer Compatibility Program. HNF-SD-WM-OCD015 Rev. 2, Lockheed Martin Hanford Corp., Richland, Washington.

Fowler KD. 1995. Tank Farm Waste Compatibility Program. WHC-SD-WM-OSD-015 Rev. 1, Westinghouse Hanford Co., Richland, Washington.

Hu TA. 1999. Empirical Rate Equation Model and Rate Calculations of Hydrogen Generation for Hanford Tank Waste. HNF-3851 Rev. 0, Lockheed Martin Hanford Corp., Richland, Washington.

Kubic WL and AV Belooussov. 1999. Dilution to Eliminate and Prevent Crust Formation in Tank 241-SY-101. LA-UR-99-3770, Los Alamos National Laboratory, New Mexico.

Mahoney LA, ZI Antoniak, JM Bates, and ME Dahl. 1999. Retained Gas Sampling Results for the Flammable Gas Program. PNNL-13000 Rev. 0, Pacific Northwest National Laboratory, Richland, Washington.

McCain DJ. 1999. Results of Vapor Space Monitoring of Flammable Gas Watch List Tanks. HNF-SD-WM-TI-797 Rev. 4, Fluor Daniel Hanford Inc., Richland, Washington.

Meyer PA and BE Wells. February 2000. "Understanding Gas Release Events in Hanford Double-Shell Tanks." Proceedings of Waste Management 2000, Tucson, Arizona. 
Meyer PA, ME Brewster, SA Bryan, G Chen, LR Pederson, CW Stewart, and G Terrones. 1997. Gas Retention and Release Behavior in Hanford Double-Shell Waste Tanks. PNNL-11536 Rev. 1, Pacific Northwest National Laboratory, Richland, Washington.

Peurrung LM, LA Mahoney, CW Stewart, PA Gauglitz, LA Pederson, SA Bryan, and CL Shepard. 1998. Flammable Gas Issues in Double-Contained Receiver Tanks. PNNL-11836 Rev. 2, Pacific Northwest National Laboratory, Richland, Washington.

Rassat SD, CW Stewart, BE Wells, JM Cuta, WL Kuhn, ZI Antoniak, KP Recknagle, G Terrones, JH Sukamto, VV Viswanathan, and DP Mendoza. 2000. Dynamics of Crust Dissolution and Gas Release in Tank 241-SY-101. PNNL-13112, Pacific Northwest National Laboratory, Richland, Washington.

Raymond RE. 1999. Tank 241-SY-101 Surface-Level-Rise Remediation Project Plan. HNF3824 Rev. 0, Lockheed Martin Hanford Corporation, Richland, Washington.

Recknagle KP and Y Onishi Y. 1999. Transport of Tank 241-SY-101 Waste Slurry: Effects of Dilution and Temperature on Critical Pipeline Velocity. PNNL-12217, Pacific Northwest National Laboratory, Richland, Washington.

Reynolds DA. 1993. Tank 101-SY Window E Core Sample: Interpretation of Results. WHC-EP0628, Westinghouse Hanford Co., Richland, Washington.

Stewart CW. 1999. Buoyant Response of the Tank 2412-SY-101 Crust to Transfer and BackDilution. PNNL-13066, Pacific Northwest National Laboratory, Richland, Washington.

Stewart CW, JM Alzheimer, ME Brewster, G Chen, RE Mendoza, HC Reid, CL Shepard, and G Terrones. 1996. In Situ Rheology and Gas Volume in Hanford Double-Shell Waste Tanks. PNNL-11296, Pacific Northwest National Laboratory, Richland, Washington.

Stewart CW, JD Hudson, JR Friley, FE Panisko, ZI Antoniak, JJ Irwin, JG Fadeff, LE Efferding, TE Michener, NW Kirch, and DA Reynolds. 1994. Mitigation of Tank 241-SY-101 by Pump Mixing: Results of Full Scale Testing. PNL-9959, Pacific Northwest National Laboratory, Richland, Washington.

Tingey JM, PR Bredt, and EH Shade. 1994. The Effects of Heating and Dilution on the Rheological and Physical Properties of Tank 241-SY-101 Waste. PNL-10198, Pacific Northwest National Laboratory, Richland, Washington. 


\section{Appendix A}

Development of Limit of Integration for Energy Ratio Model 


\section{Appendix A}

\section{Development of Limit of Integration for Energy Ratio Model}

The limit of integration for the energy ratio model, $\mathrm{h}$, is the distance the centroid of the participating gob (buoyant portion of the nonconvective layer) may travel between its initial state in the nonconvective layer and its end state at neutral buoyancy at the surface. It is assumed that the gob is a right circular cylinder in shape and has an initial thickness of $h_{\mathrm{G} 0}$ with the upper surface at the top of the nonconvective layer. Further, it is assumed that the gob does not release any gas prior to reaching its neutral buoyant position. From Archimedes principle, the weight of liquid displaced by the submerged portion of the gob must equal its weight, or

$$
\rho_{\mathrm{L}} \mathrm{V}_{\mathrm{GS}}=\rho_{\mathrm{GT}} \mathrm{V}_{\mathrm{GT}}
$$

where $\rho_{\mathrm{L}}$ is the liquid density, $\mathrm{V}_{\mathrm{GS}}$ is the submerged volume of the gob, and $\rho_{\mathrm{GT}}$ and $\mathrm{V}_{\mathrm{GT}}$ are the density and volume of the gob at its end state, respectively. The height of the gob that is submerged is given by solving Eq. (A.1) for $\mathrm{V}_{\mathrm{GT}}$ and dividing by the gob cross-sectional area or $\mathrm{A}_{\mathrm{GT}}$ :

$$
h_{S}=\frac{\rho_{G T}}{\rho_{L}} \frac{V_{G T}}{A_{G T}}=\frac{\rho_{G T}}{\rho_{L}} h_{G T}
$$

where $h_{G T}$ is the thickness of the gob at its end state.

The volume of the gob at its end state at the waste surface is assumed to differ from its initial volume only by gas expansion due to reduction in hydrostatic pressure. This is expressed by

$$
\mathrm{V}_{\mathrm{GT}}=\mathrm{V}_{\mathrm{GasT}}+\mathrm{V}_{\mathrm{NGasT}}=\mathrm{p}_{\mathrm{S}} \mathrm{V}_{\mathrm{G} 0} \alpha_{0}+\left(1-\alpha_{0}\right) \mathrm{V}_{\mathrm{G} 0}
$$

where $\mathrm{V}_{\mathrm{GasT}}$ and $\mathrm{V}_{\mathrm{NGasT}}$ are the gas and non-gas volumes of the gob at the waste surface, $\mathrm{V}_{\mathrm{G} 0}$ and $\alpha_{0}$ are the initial volume and void fraction of the gob, respectively, and $p_{s}$ is the average pressure of the gas in the nonconvective layer, defined by Eq. (3.5). The density of the gob at the waste surface may be expressed using conservation of mass between the two states:

$$
\rho_{\mathrm{GT}}=\left(1-\frac{\mathrm{p}_{\mathrm{S}} \mathrm{V}_{\mathrm{G} 0} \alpha_{0}}{\mathrm{p}_{\mathrm{S}} \mathrm{V}_{\mathrm{G} 0} \alpha_{0}+\left(1-\alpha_{0}\right) \mathrm{V}_{\mathrm{G} 0}}\right) \rho_{\mathrm{NCL}}
$$

where $\rho_{\mathrm{NCL}}$ is the nonconvective layer density.

The expansion of the gob as it rises from its initial position to its neutrally buoyant position is assumed to occur both in the horizontal and vertical directions such that the aspect ratio of the gob remains constant. The ratio of the diameter of the gob to its height at the waste surface is then given by 


$$
\frac{\mathrm{D}_{\mathrm{GT}}}{\mathrm{h}_{\mathrm{GT}}}=\frac{\mathrm{D}_{\mathrm{G} 0}}{\mathrm{~h}_{\mathrm{G} 0}}
$$

with $\mathrm{D}_{\mathrm{G} 0}$ and $\mathrm{h}_{\mathrm{G} 0}$ denoting the initial diameter and thickness of the gob, respectively.

From Eq. (A.3) and (A.5), the height of the gob at the surface can be computed by

$$
\mathrm{h}_{\mathrm{GT}}=\mathrm{h}_{\mathrm{G} 0}\left[\mathrm{p}_{\mathrm{S}} \alpha_{0}+\left(1-\alpha_{0}\right)\right]^{\frac{1}{3}}
$$

The gob submergence at the surface can then be determined from Eq. (A.2), (A.4), and (A.6):

$$
\mathrm{h}_{\mathrm{S}}=\frac{\rho_{\mathrm{NCL}}}{\rho_{\mathrm{L}}} \mathrm{h}_{\mathrm{G} 0}\left(\mathrm{p}_{\mathrm{S}} \alpha_{0}+\left(1-\alpha_{0}\right)\right)^{-\frac{2}{3}}\left(1-\alpha_{0}\right)
$$

The upper limit of integration, $h$, is the elevation of the gob centroid at its end state, which is computed by

$$
\mathrm{h}=\frac{\mathrm{h}_{\mathrm{G} 0}}{2}+\mathrm{h}_{\mathrm{LGT}}+\frac{\mathrm{h}_{\mathrm{GT}}}{2}-\mathrm{h}_{\mathrm{S}}
$$

The height of the convective liquid $\left(\mathrm{h}_{\mathrm{LGT}}\right)$ after the gob has risen to the waste surface is necessarily the initial height plus the increase due to gob expansion minus the decrease due to the gob no longer being completely submerged. However, for the tanks under consideration, this effect contributes approximately $0.01 \%$ to the total distance the gob may travel. Therefore, it is neglected, and the initial convective layer depth of $h_{L}$ is used without modification. Substituting Eq. (A.6) and (A.7) into Eq. (A.8), the limit of integration is given as

$$
\mathrm{h}=\mathrm{h}_{\mathrm{L}}+\mathrm{h}_{\mathrm{G} 0}\left\{\frac{1}{2}+\frac{1}{2}\left[\mathrm{p}_{\mathrm{S}} \alpha_{0}+\left(1-\alpha_{0}\right)\right]^{\frac{1}{3}}-\frac{\rho_{\mathrm{NCL}}}{\rho_{\mathrm{L}}}\left(1-\alpha_{0}\right)\left[\mathrm{p}_{\mathrm{S}} \alpha_{0}+\left(1-\alpha_{0}\right)\right]^{-\frac{2}{3}}\right\}
$$


Appendix B

Uncertainty Distributions for Model Input Parameters 


\section{Appendix B}

\section{Uncertainty Distributions for Model Input Parameters}

Table B.1. Assumed Uncertainty Distributions for Model Input Parameters

\begin{tabular}{|c|c|c|}
\hline Parameter & Value and units & Uncertainty \\
\hline Transfer volume SY-101 to SY-102 & $525 \mathrm{kgal}$ & $\mathrm{Sd}=2.9 \mathrm{kgal}$ \\
\hline SY-101 initial slurry density & $1600 \mathrm{~kg} / \mathrm{m}^{3}$ & $\pm 5 \%$ \\
\hline Solid particle density & $2200 \mathrm{~kg} / \mathrm{m}^{3}$ & $\pm 13 \%$ \\
\hline Saturated liquid density & $1485 \mathrm{~kg} / \mathrm{m}^{3}$ & $\mathrm{Sd}=41.6 \mathrm{~kg} / \mathrm{m}^{3}$ \\
\hline $\begin{array}{l}\text { SY-101 mixture apparent water } \\
\text { density }\end{array}$ & $1045 \mathrm{~kg} / \mathrm{m}^{3}$ & $\mathrm{Sd}=10.3 \mathrm{~kg} / \mathrm{m}^{3}$ \\
\hline $\begin{array}{l}\text { SY-101 mixture apparent dissolved } \\
\text { solid density }\end{array}$ & $2226 \mathrm{~kg} / \mathrm{m}^{3}$ & $\mathrm{Sd}=110 \mathrm{~kg} / \mathrm{m}^{3}$ \\
\hline Dilution factor & 0.9 & $\pm 4 \%$ \\
\hline $\begin{array}{l}\text { Ratio of solids to water mass at } \\
\text { saturation at } 50^{\circ} \mathrm{C}\end{array}$ & 1.267 & $\mathrm{Sd}=0.14$ \\
\hline Gas fraction in settled solids layer & 0.08 & $\pm 40 \%$ \\
\hline $\begin{array}{l}\text { Solids volume fraction in settled } \\
\text { solids layer }\end{array}$ & 0.3 & $\pm 30 \%$ \\
\hline $\begin{array}{l}\text { Fraction of solids dissolved by } \\
\text { dilution }\end{array}$ & 0.6 & $0.6-0.85$ \\
\hline Maximum waste level in SY-102 & $10.4 \mathrm{~m}$ & $\pm 3 \%$ \\
\hline Stationary layer depth in SY-102 & $0.65 \mathrm{~m}$ & $\pm 20 \%$ \\
\hline $\begin{array}{l}\text { Supernatant liquid density in } \\
\text { SY-102 }\end{array}$ & $1250 \mathrm{~kg} / \mathrm{m}^{3}$ & $1250-1350$, triangular \\
\hline Stationary layer density in SY-102 & $1550 \mathrm{~kg} / \mathrm{m}^{3}$ & $\pm 4 \%$ \\
\hline $\begin{array}{l}\text { Gas generation rate of SY-101 } \\
\text { waste after dilution }\end{array}$ & $0.00075629 \mathrm{~m}^{3} / \mathrm{m}^{3}$-day & $\pm 30 \%$ \\
\hline $\begin{array}{l}\text { Hydrogen volumetric gas } \\
\text { generation rate in SY-102 }\end{array}$ & $0.03 \mathrm{~m}^{3} /$ day & $\pm 40 \%$ \\
\hline $\begin{array}{l}\text { Mole fraction of hydrogen in } \\
\text { SY-102 }\end{array}$ & 0.65 & $0.50-0.65$, triangular \\
\hline Yield stress in settled solids layer & $116 \mathrm{~Pa}$ & $50-200$, beta with peak at 116 \\
\hline $\begin{array}{l}\text { Average hydrogen concentration of } \\
\text { gas release }\end{array}$ & 0.75 & $0.65-0.75$, triangular \\
\hline Hydrogen lower flammability limit & 0.04 & $0.38-0.04$, triangular \\
\hline Waste temperature in SY-102 & $301 \mathrm{~K}$ & $300-311$, triangular \\
\hline
\end{tabular}


Notes:

- A normal distribution is applied unless indicated otherwise.

- Sd indicates the standard deviation of the normal distribution; a percent value indicates the range on each side of the typical value. In the case of percentage, $\pm x / 100^{*}$ mean is considered as the range. When applied to a normal distribution, $s d=(x / 100 *$ mean $) / 3.5$. For a normal distribution, $3.5 * \mathrm{sd}$ is 99.98 percentile.

- A trianglar distribution has the range as indicated and the peak at the typical value (one end of the range). 


\section{Distribution}

No. of

Copies

Offsite

2 Office of Scientific and Technical Information

Onsite

8 DOE Richland Operations Office

CA Groendyke (6)

DH Irby

JS Shuen

H6-60

H6-60

H6-60

14 PHMC Team

WB Barton

RE Bauer

JR Biggs

RJ Cash

JM Conner

SD Estey

JM Grigsby
R2-11

$\mathrm{S} 7-70$

S7-70

R1-44

R2-11

R2-11

R1-44
No. of

Copies

GD Johnson

R1-44

NW Kirch

R2-11

CE Leach

R1-44

RE Raymond

S7-70

DA Reynolds

R2-11

TCSRC

R1-10

CHG Corr. Control

H6-08

26 Pacific Northwest National Laboratory

JM Bates

K7-15

SQ Bennett

JW Brothers (3)

K7-90

$\mathrm{G}$ Chen

K9-20

JM Cuta

K5-12

$\mathrm{K} 7-15$

PA Gauglitz

ЛL Huckaby

K6-28

K7-15

WL Kuhn

K $7-15$

LA Mahoney

$\mathrm{K} 7-15$

PA Meyer

$\mathrm{K} 7-15$

SD Rassat

K6-28

CW Stewart (3)

K7-15

BE Wells (5)

K7-15

Information Release (5)

K1-06

Distr. 1 